\title{
COMPARISON OF LIVER BLOOD FLOW VALUES ESTIMATED \\ BY THE BROMSULPHALEIN AND BY THE RADIOGOLD METHOD
}

\author{
BY HERBERT VETTER, GEORG GRABNER, RUDOLF HÖFER, ANTON NEUMAYR, \\ AND OTTO PARZER $\dagger$ \\ (From the Radioisotopes Laboratory, Second Medical University Clinic, University of Vienna, \\ Vienna, Austria)
}

(Submitted for publication July 19, 1955; accepted April 3, 1956)

In a previous paper (1) we have described a method of following the disappearance of intravenously injected colloidal radioactive gold from the circulation in man and have discussed the possibilities of calculating liver blood flow from the disappearance rate constant as the fraction of blood volume perfusing the liver per unit time. If liver blood flow values estimated in this way could be demonstrated to be correct this method should have many advantages over other methods currently in use: it does not require hepatic vein catheterization; with only one blood sample withdrawn for determination of hematocrit and plasma volume, it does not involve any undue blood loss to the patient; being exceedingly simple and mechanized to a considerable extent by the use of counting rate meters and recorders, it can be carried out by a single technician; it can be repeated several times without exposing the patient to any risk thereby enabling observation of changes in hepatic circulation over any period of time.

Hepatic blood flow values estimated by this method in 25 normal subjects (18 males and 7 females) were found to average $1310 \mathrm{ml}$. per min. (1) and thus to be somewhat lower but still within the range of normal values reported by other groups who used the bromsulphalein or other methods. However, even this difference might not have been a real one. In this laboratory the observed venous hematocrit is corrected for trapped plasma and for the uneven distribution of cells and plasma within the whole body circulation. This leads to a blood volume which is about 14 per cent lower than that which is calculated from the uncorrected hematocrit. None of the groups of investigators whose results have been compared

$\dagger$ Dr. Parzer died from a cerebral tumor on September 11,1955 , at the age of 28 . For all of us, it has been a privilege to know him and to work with him. with the average normal radiogold results, appear to have used any correction of the hematocrit. It might, therefore, well be that the difference between average hepatic blood flows estimated by these two methods in different groups of normal subjects has been caused by the difference in the methods of calculating blood volume.

However, a few experiments designed to investigate the efficiency of the liver phagocytes to remove the colloid particles from the blood passing through the liver, indicated that the radiogold method underestimates the true hepatic blood flow by almost 20 per cent (1). If this is true a direct comparison of $\mathrm{BSP}$ and radiogold results should reveal a real difference in the calculated flow values. Simultaneous estimations of hepatic blood flow by these two methods were, therefore, performed in 15 subjects the results of which are presented in this paper.

\section{METHODS}

Material. The subjects studied were hospitalized patients in whom for diagnostic purposes a heart or hepatic vein catheterization was warranted. Therefore, none of the subjects could be considered to be "normal."

Catheterization. In each patient a Cournand catheter connected with a slowly running saline-heparin infusion was first introduced into the pulmonary artery under fluoroscopic control. Two blood samples were taken from there at two different positions and another one from either the brachial or the femoral artery, their oxygen content being subsequently determined with a Van Slyke apparatus. Oxygen consumption was measured with a Knipping spirometer and cardiac output calculated from the data thus obtained. The catheter was then advanced into a right hepatic vein in all patients with one exception where only a left hepatic vein could be reached. Following the estimation of hepatic blood flow by the BSP and by the radiogold method, blood samples from the hepatic vein were taken for determination of oxygen content. Wedged liver capillary pressure was measured in most patients. In all but two patients the pulmonary artery was then again catheterized and a further double 
estimation of cardiac output was carried out. In the cardiac cases pulmonary artery, wedged pulmonary capillary, right atrial, and brachial or femoral artery pressures were measured using two Tybjaerg-Hansen manometers. Since the data on cardiac output and hepatic oxygen consumption and the pressure data have no bearing on the matter under discussion they will be omitted from this paper.

Bromsulphalein. "Bromthalein"-Merck was used throughout this study. Each patient was first given a single dose of $5 \mathrm{mgm}$. per $\mathrm{Kg}$. body weight and its disappearance from the circulation was followed for $45 \mathrm{~min}$ utes. Three to 5 days later, catheterization was performed and immediately following a priming dose of 150 mgm., a constant i.v. infusion was started using a motordriven syringe at a rate which, varying between 1 and $7 \mathrm{mgm}$. per min. in individual cases, was adjusted to the removal rate estimated from the clearance of the single BSP dose. Starting $10 \mathrm{~min}$. later blood samples were taken at frequent intervals from the hepatic vein and from either the brachial or the femoral artery. A ZeissOpton photoelectric spectrophotometer was used to measure dye concentrations at a wave-length of $5800 \AA$. By plotting the concentration values on semi-log paper the rate of removal of BSP from the circulation was calculated from the infusion rate and from the change in peripheral BSP concentration per min., multiplied by the plasma volume. Hepatic blood flow (EHBF) and BSP extraction by the liver ( $E_{\mathrm{BSP}}$ ) was calculated as described by Bradley, Ingelfinger, Bradley, and Curry (2).
Colloidal radiogold. External measurements of the disappearance rate of colloidal $\mathrm{Au}^{198}$ from the blood stream were done during the time of BSP infusion. The procedure was carried out as previously described (1) with the exception that a shielded scintillation counter fitted with a $1 \frac{1}{2} \times 1$ inch thallium-activated sodium iodide crystal was used instead of the lead cathode GMcounter, the opening of the shielding placed close to the skin over one of the thighs. A counting rate meter was used to read off counts per second at intervals of $1 \mathrm{~min}$. and recently an ink-writer was attached to enable automatic recording. Colloidal $\mathrm{Au}^{188}$ produced by A.E.R.E., Harwell, now obtainable with a specific activity of up to $100 \mathrm{mc}$. per ml., was again used. It might be worthwhile to note that according to Lahr, Olsen, Gleason, and Tabern (3), the American-produced "Aurcoloid" has an average particle size of only about one-fifth of that of the British-made colloidal radiogold and might, therefore, be unsuitable for this type of experiment.

Blood volume. Whole body hematocrit and plasma volume were determined and blood volume was calculated as previously described (1) with the exception that for determination of plasma volume, instead of $\mathrm{T}-1824$, human serum albumin labeled with $\mathrm{I}^{132}$ was used in a few cases.

\section{RESULTS}

It will be seen from the data presented in Table I that hepatic blood flow values estimated by the radiogold method (LMV) were, on the average,

TABLE I

Data on liver blood flow and BSP extraction estimated by the radiogold and by the BSP method in 15 subjects with varying degrees of hepatic dysfunction *

\begin{tabular}{|c|c|c|c|c|c|c|c|c|c|c|c|}
\hline Name & Diagnosis & WBHT & BV & k & LMV & A & $\mathrm{H}$ & $\mathbf{R}$ & $\mathrm{EHBF}$ & EBSP & $\mathrm{LMV} / \mathrm{EHBF}$ \\
\hline TOM & Cirrhosis & 43.1 & 4,410 & .0815 & 360 & 2.03 & 1.49 & 2.38 & 785 & 26.4 & .459 \\
\hline HOF & Posthepatitis & 34.6 & 5,550 & .182 & 1,010 & 1.24 & .66 & 6.50 & 1,715 & 46.8 & .590 \\
\hline WEIN & Posthepatitis & 32.4 & 4,220 & .159 & 670 & 2.52 & 1.93 & 4.48 & 1,120 & 23.4 & .598 \\
\hline SIM & Mitral stenosis & 34.8 & 4,310 & .071 & 305 & 4.62 & 2.26 & 7.37 & 480 & 51.0 & .635 \\
\hline POL & Mitral stenosis & 35.0 & 3,880 & .115 & 445 & 2.50 & 1.41 & 4.59 & 645 & 43.6 & .690 \\
\hline STE & Pericarditis & 40.3 & 5,010 & .1415 & 710 & 2.27 & 1.44 & 5.06 & 1,025 & 36.4 & .693 \\
\hline MAI & Colitis & 32.9 & 5,700 & .128 & 730 & .96 & .24 & 5.00 & 1,035 & 75.0 & .705 \\
\hline ZEC & Lues latens & 29.0 & 5,750 & .124 & 715 & 1.32 & .57 & 4.79 & 900 & 56.8 & .795 \\
\hline BOG & Appendicitis & 37.2 & 6,050 & .141 & 855 & 1.03 & .10 & 6.00 & 1,030 & 90.5 & .830 \\
\hline WAW† & Ductus botalli & 36.7 & 4,520 & .289 & 1,305 & & & & 1,460 & & .895 \\
\hline WEIH & Posthepatitis & 39.2 & 5,280 & .161 & 850 & 2.28 & .82 & 7.53 & 850 & 64.0 & 1.000 \\
\hline OBE & Mitral stenosis & 39.3 & 5,290 & .1135 & 600 & 1.18 & .10 & 3.86 & 595 & 91.5 & 1.010 \\
\hline SIK & Diabetes & 29.8 & 5,240 & .231 & 1,210 & .78 & .10 & 5.00 & 1,050 & 87.2 & 1.151 \\
\hline NED & Postcholangitis & 28.8 & 5,380 & .180 & 970 & .66 & .37 & 1.56 & 750 & 44.0 & 1.291 \\
\hline KLI & Cirrhosis & 36.3 & 5,990 & .136 & 815 & 1.33 & .91 & 1.67 & 620 & 31.6 & 1.313 \\
\hline Mean & & & & & & & & & & & .844 \\
\hline
\end{tabular}

* WBHT $=$ Whole body hematocrit, in per cent.

$\mathrm{BV}=$ Blood volume, corrected for blood loss during experiment, in $\mathrm{ml}$

$\mathrm{k}=$ Disappearance rate constant of $\mathrm{Au}^{198}$, in min.-1

LMV = Liver blood flow, calculated from BV and $\mathrm{k}$, in $\mathrm{ml}$. per $\mathrm{min}$

$\mathrm{A}=$ Peripheral BSP concentration, in mgm. per cent.

$\mathrm{H}=$ Hepatic vein BSP concentration, in mgm. per cent.

$\mathrm{R}=\mathrm{BSP}$ removal rate, in mgm. per min.

$\mathrm{EHBF}=$ Liver blood flow, calculated from R, WBHT, and A-H difference, in $\mathrm{ml}$. per min

$\mathrm{E}_{\mathrm{BSP}}=\mathrm{BSP}$ extraction, calculated from $\mathrm{A}$ and $\mathrm{A}-\mathrm{H}$ difference, in per cent.

$\dagger$ Detailed BSP data lost after completion of EHBF calculation. 
84.4 per cent of those obtained by the BSP method $(\mathrm{EHBF})$. There was considerable scatter around this mean, the factor $\mathrm{LMV}$ over EHBF ranging from 0.459 to 1.313 . In four cases $\mathrm{LMV}$ was found to exceed EHBF, in one case both values were identical, and in the remaining 10 cases LMV was lower than EHBF (Figure 1). In most patients, liver blood flow values calculated by either method were found to be lower than normal.

\section{DISCUSSION}

The average difference of about 16 per cent between the radiogold and the BSP values could easily be explained by the fact that the radiogold method by neglecting incomplete removal of the colloid material by the liver phagocytes underestimates true hepatic blood flow. However, the large individual scatter and the observation in four cases of an EHBF which was lower than the radiogold value, appear to indicate that either the radiogold or the $\mathrm{BSP}$ method or both may be subject to considerable errors.

The nature and the magnitude of the errors involved in the radiogold method have been, up to now, not explored adequately. The results of some preliminary experiments permit only tentative statements which might, in the light of further observation, require drastic revision:

1. Though it was found that, on the average, 18 per cent of the large and medium-sized colloid particles are not removed by the liver phagocytes during their first passage through the liver capillaries, this figure is based on but 3 measurements of radiogold concentration in hepatic vein blood (1). Though published results obtained in animals $(4,5)$ suggest that this average is probably of the correct order, the magnitude of the individual variations around this mean needs to be established by further work.

2 . The radiogold method is based on the assumption that mixing of the injected colloid within the circulating blood volume is very rapid. That this is not always the case has been shown by Dobson, Warner, Finney, and Johnston (6) and by Neumayr, Falkner, and Vetter ( 7 ) by comparison with the simultaneously observed mixing curve of $\mathrm{T}-1824$. It could be demonstrated that, on the average, the influence of incomplete mixing can be neglected (7); however, an occasional delay in

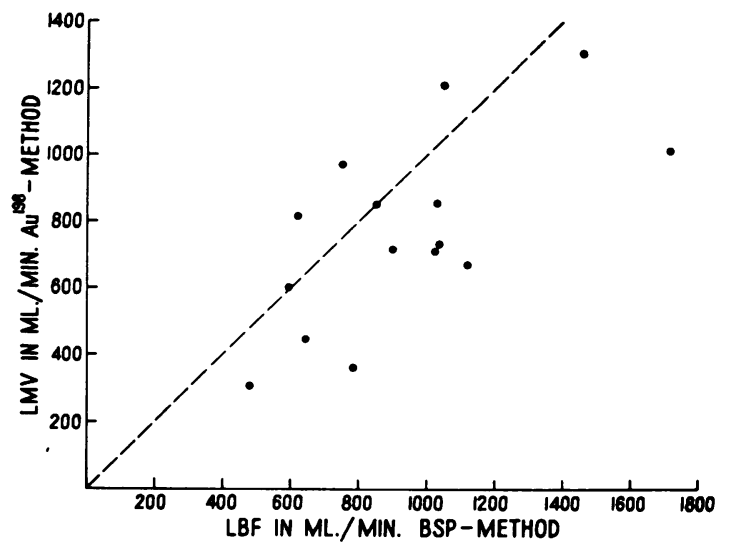

Fig. 1. Comparison of Liver Blood Flow Values Obtained by the Radiogold and by the BromsulphaLEIN METHOD

The dashed line represents a $1: 1$ relation.

mixing could have contributed to the observed variations in individual differences between the calculated flow values.

3. The results of experiments on the distribution of intravenously injected colloidal radiogold in animals $(3,8,9)$ indicate that small fractions of the administered dose are picked up by the adrenals, the kidneys, and the bone marrow. In postmortem studies of human subjects given therapeutic doses of the British radiogold intravenously, between 90 and 95 per cent could be accounted for in liver and spleen (10). It is probable that the remaining fractions are formed by the very small particles which pass the liver and spleen anyway, and whose disappearance curve from the circulation has to be separated graphically from the disappearance curve of the large and medium-sized particles. The error arising from this source should, therefore, be small; moreover, the removal rate of the small particles appears to be several times slower than that of the larger particles ( 7$)$.

4. The nature of the colloid used is apparently of no importance provided the particle size does not differ greatly. Similar removal rates for different colloids with the exception of yttrium compounds have been observed in various animals (4, 11-13). In this laboratory, colloidal iron saccharate labeled with $\mathrm{Fe}^{59}$ has been observed to disappear from the human circulation at rates which did not significantly differ from the disappearance rates of colloidal radiogold (14). 
5. If the amount of colloidal radiogold injected is kept below $250 \mu \mathrm{gm}$., "saturation" of the uptake mechanisms in the liver and spleen is unlikely to occur (1).

The nature and magnitude of the errors involved in the BSP method are far better known. Throughout this study all efforts were made to follow the procedures of infusing, timing of sample withdrawal, and of measuring BSP plasma concentration described by Bradley, Ingelfinger, Bradley, and Curry (2) as closely as possible. The results of several experiments had to be discarded because either the change in peripheral BSP concentration was too rapid or $\mathrm{BSP}$ extraction by the liver was too small, but even in the remaining cases considerable difficulties were encountered in the calculation of EHBF from the BSP data. Though these difficulties may have been aggravated to some extent by the inexperience of the authors with this method, some of the errors appeared to be unavoidable:

1. In most cases a steady state between BSP infusion and BSP removal could not be reached and $\mathrm{BSP}$ extraction by the liver decreased steadily during the experiment. Since this decrease was not accompanied by an immediate and corresponding increase in peripheral BSP concentration the calculated EHBF figures rose steadily. Though in some cases hepatic blood flow might have indeed changed it is improbable that it had changed in the same direction and to such an extent in so many cases. Moreover, cardiac output more often decreased than increased during the experiment. Thus, it was quite difficult to decide which of the several $\mathrm{EHBF}$ and $\mathrm{E}_{\mathrm{BSP}}$ values which could be calculated during the period from 10 to $45 \mathrm{~min}$. after starting the infusion, should be taken to come closest to the correct value. As a routine procedure that value was taken which was calculated from a period of time during which peripheral BSP concentration remained constant or nearly so, usually the 25 to 30-min. period. Though in these subjects the increase in peripheral BSP concentration which should follow a fall in BSP extraction in case the flow remains constant, was usually delayed by 5 to $10 \mathrm{~min}$., the authors believe that the fall in calculated $\mathrm{E}_{\mathrm{BSP}}$ figures was caused by a progressive impairment of the ability of the liver to remove $\mathrm{BSP}$ from the circulation. The same mechanism has been shown by Mendeloff, Kramer, Ingelfinger, and Bradley (15) to be responsible for the so-called "saturation effect" which is frequently observed after a single intravenous BSP dose. Even in normal cases the rate of BSP excretion into the bile is consistently below the rate of BSP removal by the liver parenchyma $(16,17)$; since the limiting factor would be the volume of the BSP space within the liver, after some time following injection the removal rate must slow down to the rate of biliary excretion. In cases with hepatic dysfunction it is likely that the biliary excretion rate as well as the volume of the BSP space is decreased and, in fact, the "saturation effect" has been observed more frequently in patients with hepatic disorders (18-20). In the present series the "saturation effect" has been seen after a single BSP dose in five cases. The observation that in these cases the differences between the radiogold and the BSP flow values were, on the average, 31 per cent whereas in the cases without "saturation" the average difference was only 8 per cent would indicate that the progressive impairment of $\mathrm{BSP}$ extraction by the liver might have contributed to inaccuracies in the estimation of EHBF.

2. Neither a rise of the peripheral BSP level over $4 \mathrm{mgm}$. per cent nor a fall below $1 \mathrm{mgm}$. per cent appeared to have been a major source of error, the differences between the calculated flows being evenly distributed over the whole range of peripheral BSP concentrations.

3. The original work on the BSP method was based on the assumption that BSP is removed from the circulation exclusively by the liver (2). However, it has been recently shown by Brauer, Pessotti, and Krebs (21) that in dogs after prolonged infusion at least 20 per cent of the infused BSP dose is found in other organs, especially the skeletal musculature. In animals in which hepatic dysfunction was produced by pretreatment with $\mathrm{CCl}_{4}$, this figure was even considerably higher. As long as it is not firmly established that the extrahepatic BSP removal rates are several times slower than the hepatic removal rate it must be assumed that this effect leads to an overestimation of the true hepatic blood flow.

4. Entero-hepatic recirculation of BSP might have caused small inaccuracies in the calculated EHBF values. 
5. A blood sample drawn from a single hepatic vein is not representative of all the blood leaving the liver. BSP concentrations in samples withdrawn at different locations of the catheter tip in the same liver may show considerable differences in extraction of BSP by different parts of the liver, and hepatic blood flow values calculated therefrom were found to vary around the mean of all values by up to 25 per cent (2); however, it can be assumed that the magnitude of these variations is usually smaller than this maximal value.

6. In restless patients it is sometimes difficult to maintain the tip of the catheter in exactly the same position, and hepatic vein blood may be inadvertently contaminated with inferior vena cava blood. By frequent fluoroscopic controls rigorous attention has to be paid to continually proper placement of the catheter.

Both methods depend on the accuracy of the blood volume determination. In the present study the calculation of both liver blood flow values has been based on the same plasma volume and the same whole body hematocrit; therefore, any error in the estimation of these values cannot be made responsible for the individual differences between the liver blood flow values.

The majority of the known errors of the BSP method appear to lead to an overestimation of the true hepatic blood flow and this has been shown to be true by comparison with direct blood flow determinations performed by Selkurt $(22,23)$. From the limited information now available it is most probable that the radiogold method, on the other hand, underestimates the true hepatic blood flow and it seems only surprising that, on the average, the differences between both values observed in the present study have not been greater.

The large individual variations in the direction and the magnitude of the differences could be explained by delays in the assumed rapid mixing of the injected radiogold within the circulation and by variations in the efficiency of splenic and hepatic removal of the colloid material as well as by nonuniform extraction of BSP by the liver.

\section{SUM MARY}

1. In 15 patients with hepatic or cardiac disorders hepatic blood flow was estimated simultaneously by the bromsulphalein and by the radiogold method.
2. Liver blood flows calculated from the disappearance rate constant of colloidal $\mathrm{Au}^{188}$ and from the blood volume, were found to average 84.4 per cent of the values obtained by the bromsulphalein method, with large individual variations in the direction and in the magnitude of the differences.

3 . The source and magnitude of the errors involved in both methods which may have been responsible for these differences are discussed.

\section{REFERENCES}

1. Vetter, H., Falkner, R., and Neumayr, A., The disappearance rate of colloidal radiogold from the circulation and its application to the estimation of liver blood flow in normal and cirrhotic subjects. J. Clin. Invest., 1954, 33, 1594.

2. Bradley, S. E., Ingelfinger, F. J., Bradley, G. P., and Curry, J. J., The estimation of hepatic blood flow in man. J. Clin. Invest., 1945, 24, 890.

3. Lahr, T. N., Olsen, R., Gleason, G. I., and Tabern, D. L., Animal distribution of colloids of $\mathrm{Au}^{108}, \mathrm{P}^{28}$, and $\mathrm{Y}^{20}$ : an improved method of tissue assay for radioactivity. J. Lab. \& Clin. Med., 1955, 45, 66.

4. Dobson, E. L., and Jones, H. B., The behavior of intravenously injected particulate material. Its rate of disappearance from the blood stream as a measure of liver blood flow. Acta med. Scandinav., 1952, 144, suppl. 273.

5. Little, R. C., and Kelly, H. B., Removal of radioactive gold colloid by the perfused mammalian liver. Am. J. Physiol., 1953, 173, 265.

6. Dobson, E. L., Warner, G. F., Finney, C. R., and Johnston, M. E., The measurement of liver circulation by means of the colloid disappearance rate. I. Liver blood flow in normal young men. Circulation, 1953, 7, 690.

7. Neumayr, A., Falkner, R., and Vetter, H., Die Bestimmung des Blutflusses durch die Leber mit kolloidalem radioaktivem Gold. Strahlenther., 1955, Sonderb. 33, 230.

8. Sheppard, C. W., Wells, E. B., Hahn, P. F., and Goodell, J. P. B., Studies of the distribution of intravenously administered colloidal sols of manganese dioxide and gold in human beings and dogs using radioactive isotopes. J. Lab. \& Clin. Med., 1947, 32, 274.

9. Stembridge, V. A., Kniseley, R. M., and Gibbs, W., Autoradiographic distribution of intravenous colloidal gold $\left(\mathrm{Au}^{108}\right)$ in the rat. Laboratory Invest., 1953, 2, 349.

10. Fellinger, K., and Vetter, H., Radiogold-Therapie der leukämischen Erkrankungen. Strahlenther., 1955, Sonderb. 33, 175.

11. Jones, H. B., Wrobel, C. J., and Lyons, W. R., A method of distributing beta-radiation to the reticu- 
lo-endothelial system and adjacent tissues. J. Clin. Invest., 1944, 23, 783.

12. Gabrieli, E. R., The velocity at which radioactive colloids disappear from the blood. Studies on the function of the reticulo-endothelial system. Acta Physiol. Scandinav., 1951, 23, 283.

13. Wish, L., Furth, J., Sheppard, C. W., and Storey, R. H., Disappearance rate of tagged substances from the circulation of roentgen irradiated animals. Am. J. Roentgenol., 1952, 67, 628.

14. Fellinger, K., Gisinger, E., and Vetter, H., Der Stoffwechsel $\mathrm{Fe}^{59}$-markierten, kolloidalen Eisens beim Menschen. Second Symposium on Radioactive Isotopes in Clinical Medicine and Research, Bad Gastein, January 1956. Strahlenther., In press.

15. Mendeloff, A. I., Kramer, P., Ingelfinger, F. J., and Bradley, S. E., Studies with bromsulphalein. II. Factors altering its disappearance from the blood after a single intravenous injection. Gastroenterology, 1949, 13, 222.

16. Wirts, C. W., Jr., and Cantarow, A., A study of the excretion of bromsulphthalein in the bile. Am. J. Digest. Dis., 1942, 9, 101.

17. Brauer, R. W., and Pessotti, R. L., Hepatic uptake and biliary excretion of bromsulphthalein in the dog. Am. J. Physiol., 1950, 162, 565.

18. Ingelfinger, F. J., Bradley, S. E., Mendeloff, A. I., and Kramer, P., Studies with bromsulphalein. I. Its disappearance from the blood after a single intravenous injection. Gastroenterology, 1948, 11, 646.

19. Lavers, G. D., Cole, W. H., Keeton, R. W., Gephardt, M. C., and Dyniewicz, J. M., Bromsulfalein clearance. J. Lab. \& Clin. Med., 1949, 34, 965.

20. Neumayr, A., Parzer, O., and Vetter, H., Zur Problematik der Bromsulphalein-Clearance als Leberfunktionsprüfung. Deutsche Med. Wchnschr., 1954, 79, 1039.

21. Brauer, R. W., Pessotti, R. L., and Krebs, J. S., The distribution and excretion of $S^{35}$-labeled sulfobromophthalein-sodium administered to dogs by continuous infusion. J. Clin. Invest., 1955, 34, 35.

22. Selkurt, E. E., Validity of the bromsulphalein (BSP) method for estimating hepatic blood flow. Am. J. Physiol., 1953, 175, 461.

23. Selkurt, E. E., Comparison of the bromsulphalein method with simultaneous direct hepatic blood flow. Circulation Research, 1954, 2, 155. 